Supporting information for

\title{
Ionophore-based Ion-Selective Nanosensors from Brush Block Copolymer Nanodots
}

Xinfeng Du ${ }^{\# \text { a }}$, Renjie Wang ${ }^{\# \text { a }}$, Jingying Zhai ${ }^{b}$, Xiaoang $\mathrm{Li}^{\mathrm{a}}$, and Xiaojiang Xie ${ }^{*_{\mathrm{a}}}$

${ }^{a}$ Department of Chemistry, Southern University of Science and Technology, Nanshan District, Shenzhen, China

${ }^{\mathrm{b}}$ Academy for Advanced Interdisciplinary Studies, Southern University of Science and Technology, Nanshan District, Shenzhen, China

*E-mail: xiexj@sustech.edu.cn

Contents

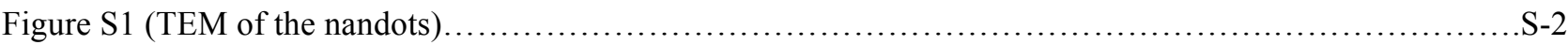

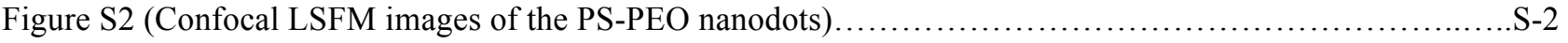

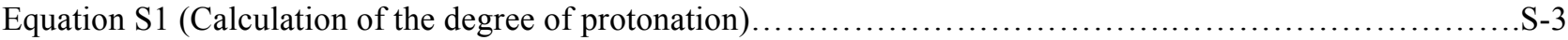

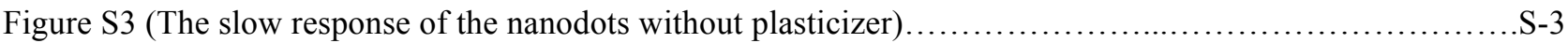

Figure $\mathrm{S} 4\left(\mathrm{Na}^{+}\right.$response of the PS-PEO nanodots containing NPOE) ..........................................

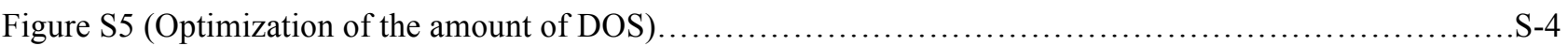

Figure S6 (Response curves in the fluorescence mode with different amount of DOS) ........................5

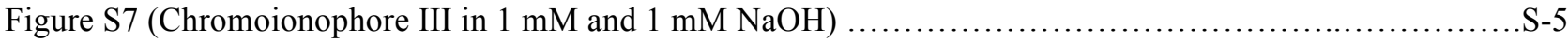

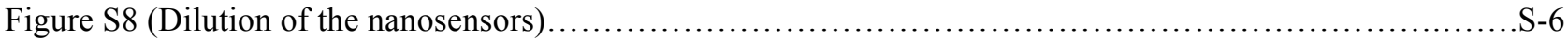

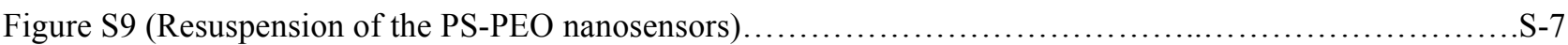

Figure S10 (Resuspension of the Pluronic F-127 \&DOS nanosensors) ..................................

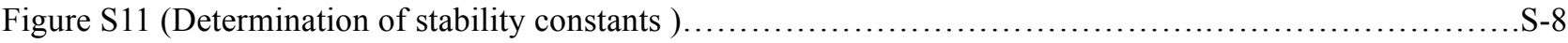

Figure S12 (Determination of sodium ion concentrations in diluted blood serum ) ........................... 9

Figure S13 (Response of the $\mathrm{K}^{+}$-selecitve nanodots in fluorescence mode)..................................

Figure S14 (Evidence of energy transfer in the PS-PEO nanosensors) ..................................... 10

Figure S15 (Confocal LSFM images of HeLa cells with ER-Tracker) ........................................

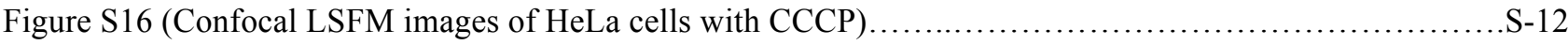

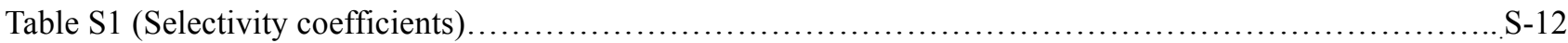



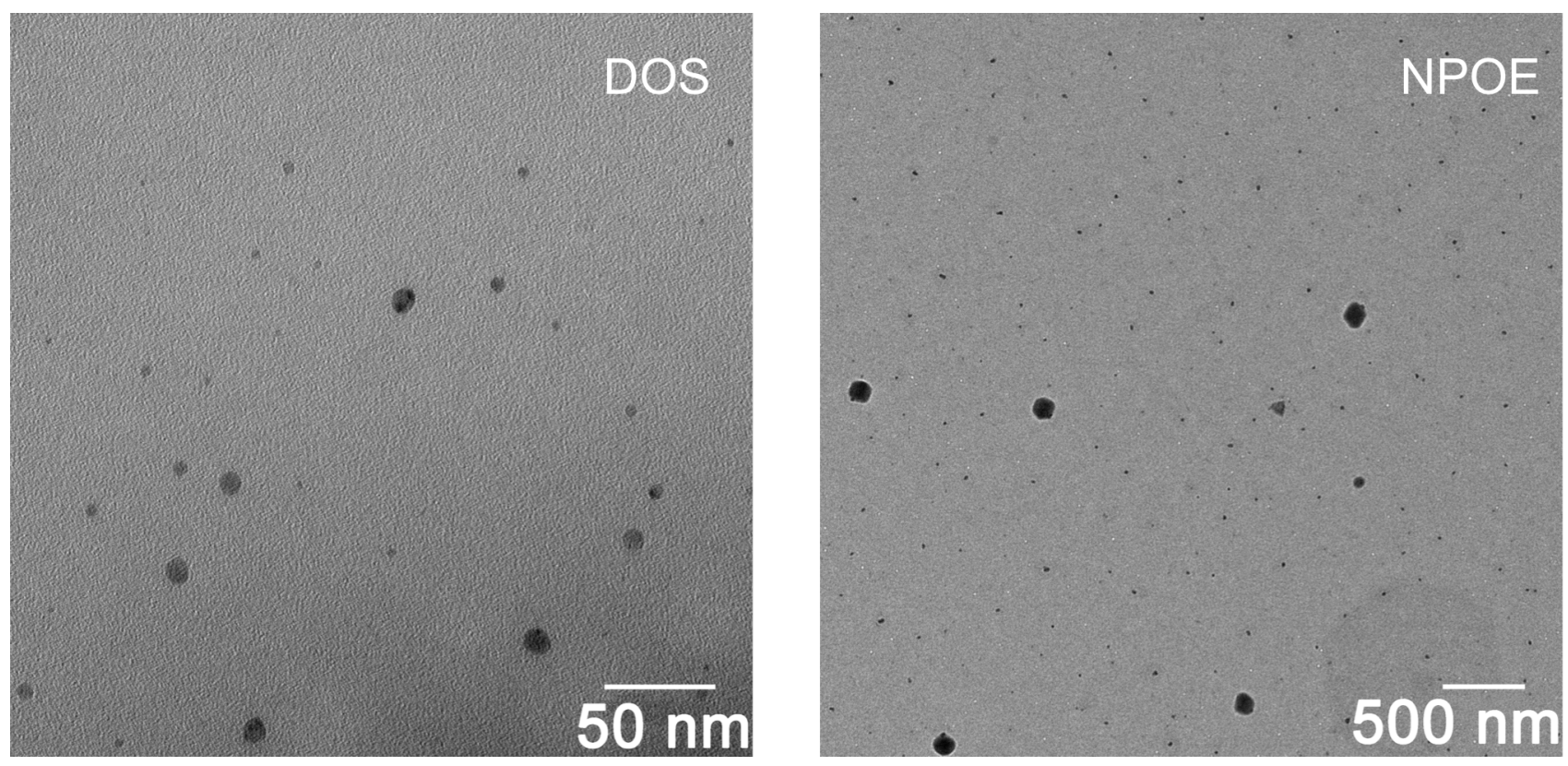

Figure S1. TEM images of the PS-PEO nandots containing DOS and NPOE, respectively.
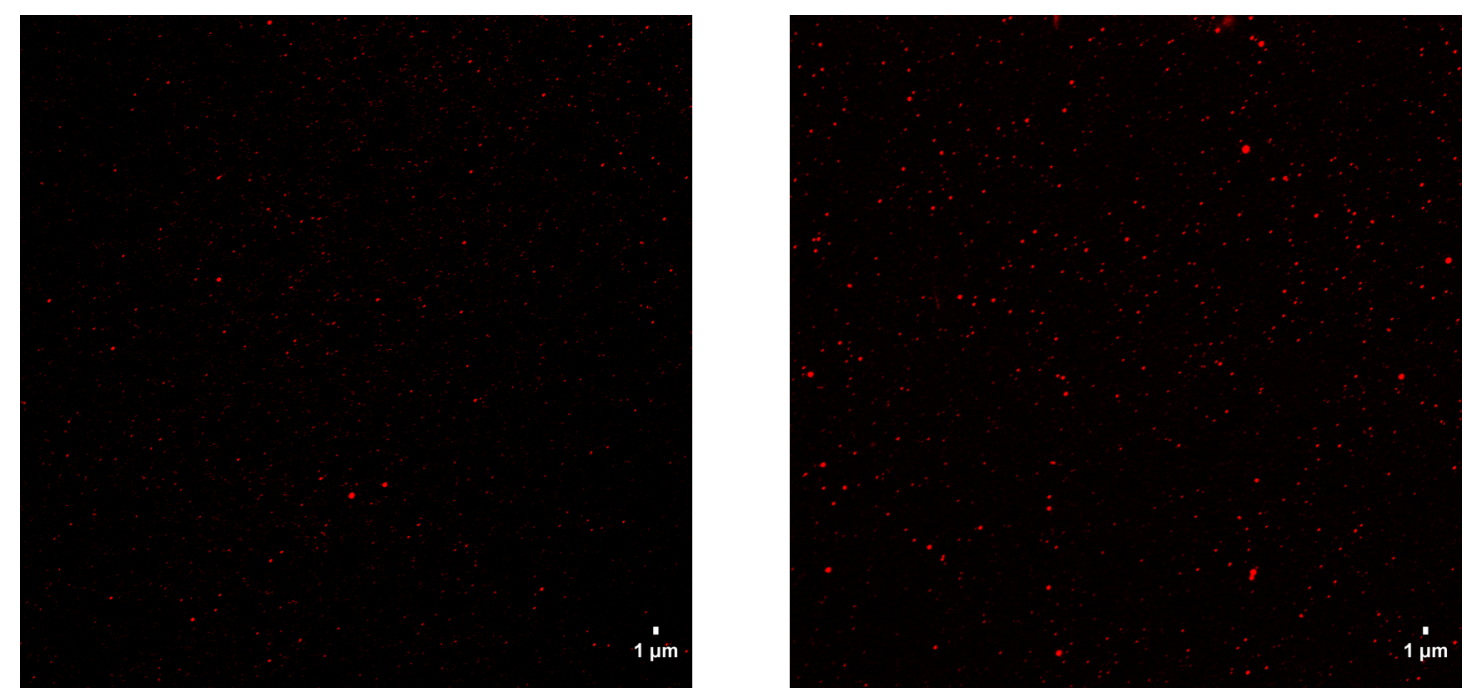

Figure S2. Confocal LSFM images of the PS-PEO nanodots containing DOS (left part) and NOPE (right part). 
The degree of protonation was calculated according to eq. S1, with A representing the absorbance at $645 \mathrm{~nm}, \mathrm{~A}_{\max }$ and $\mathrm{A}_{\mathrm{min}}$ being the maximum and minimum absorbance determined in $1 \mathrm{mM} \mathrm{HCl}$ and $\mathrm{NaOH}$, respectively.

$$
1-\alpha=\frac{A-A_{\min }}{A_{\max }-A_{\min }} \quad(\mathrm{S} 1)
$$

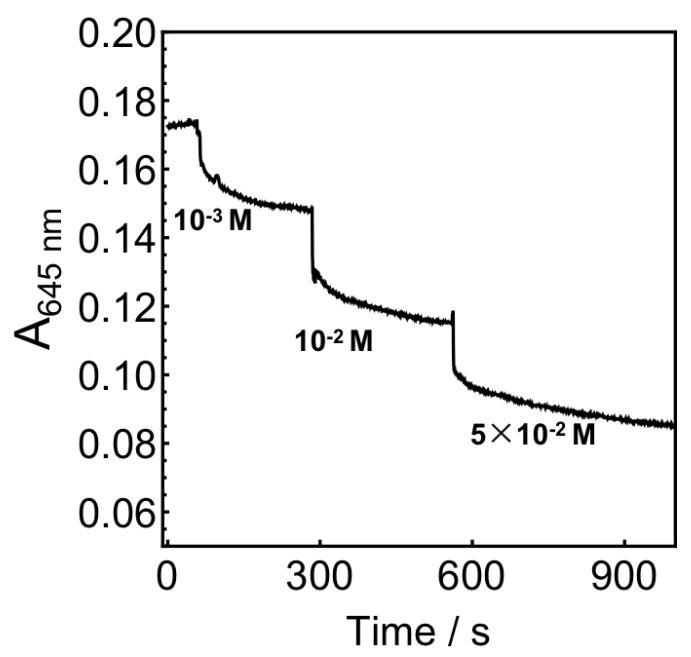

Figure S3. The slow response of the nanodots (without plasticizer) containing sodium ionophore, TFPB, and CHIII to $\mathrm{Na}^{+}$(concentrations indicated) monitored in absorbance mode at $645 \mathrm{~nm}$.

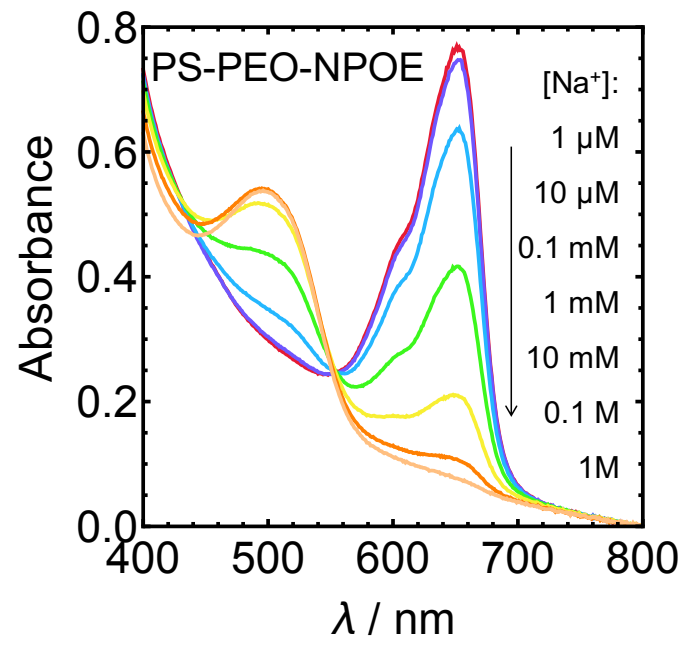

Figure S4. $\mathrm{Na}^{+}$response of the PS-PEO nanodots containing NPOE, chromoionophore III, TFPB, and sodium ionophore $\mathrm{X}$ at $\mathrm{pH}$ 7.4. 

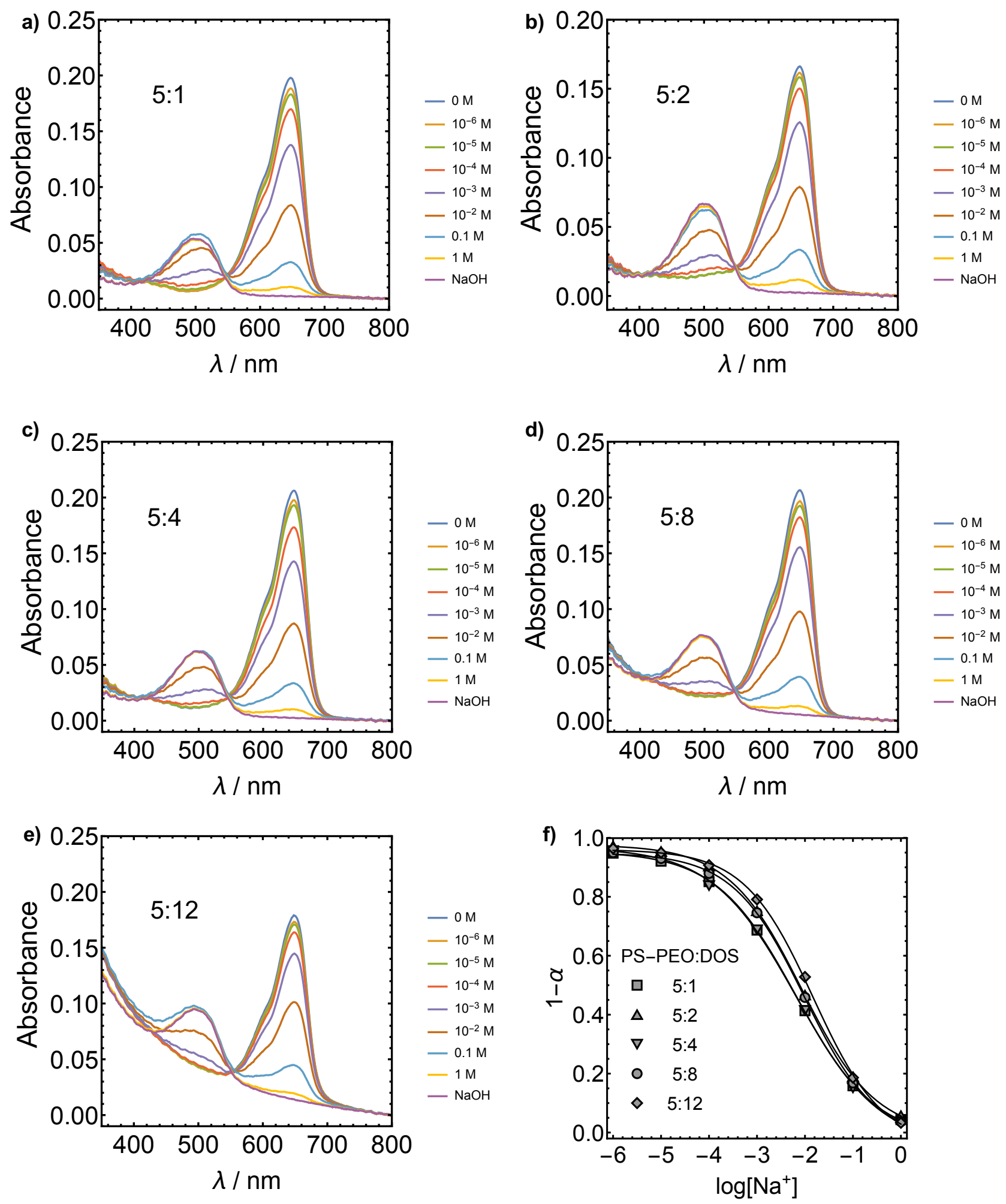

Figure S5. UV-vis absorption spectra of the $\mathrm{Na}^{+}$-selective PS-PEO nanodots containing various amount of DOS (a, b, c, d, e). The weight ratios between PS-PEO and DOS are shown in the figures. (f): Calibration curves for the $\mathrm{Na}^{+}-$ selective PS-PEO nanodots with different ratio between PS-PEO and DOS. 


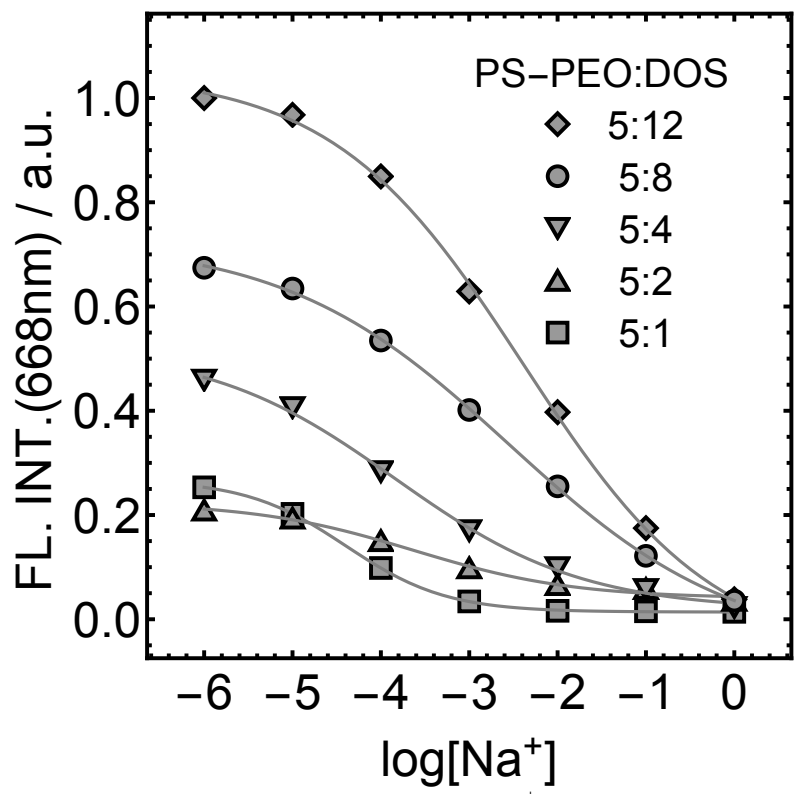

Figure S6. Response curves in the fluorescence mode for the $\mathrm{Na}^{+}$-selective PS-PEO nanodots with different ratio between PS-PEO and DOS as indicated.

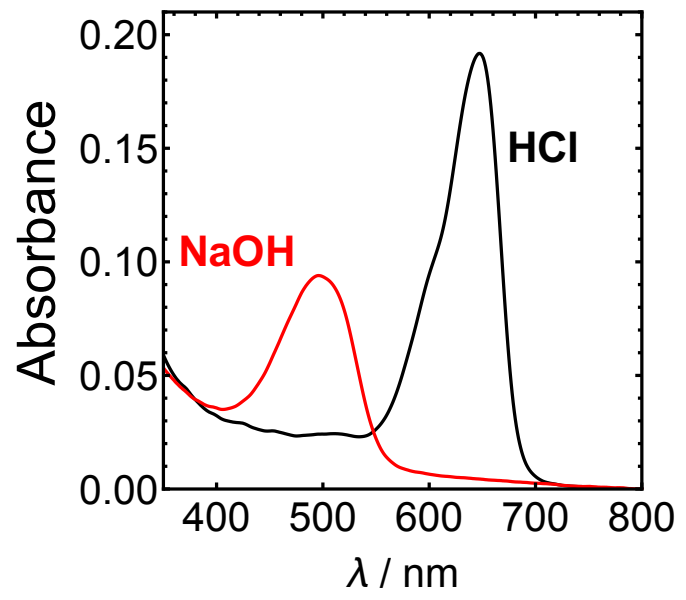

Figure S7. UV-vis absorption spectra of the nanosensors containing chromoionophore III deterimined in $1 \mathrm{mM}$ and $1 \mathrm{mM} \mathrm{NaOH}$, respectively. 

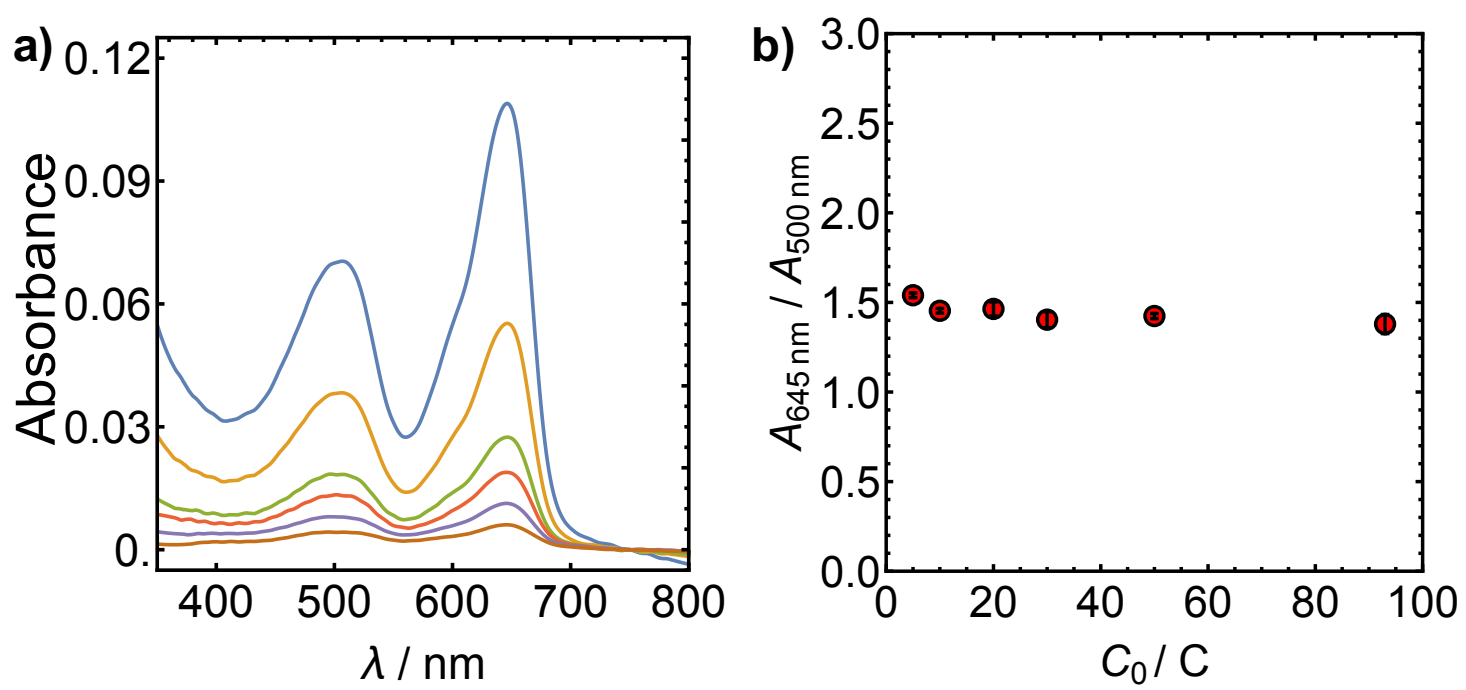

Figure S8. (a) UV-vis absorption spectra of the $\mathrm{Na}^{+}$nanosensors upon dilution. $\mathrm{Na}^{+}$concentration was kept at 10 $\mathrm{mM}$ in $\mathrm{pH} 7.4$ Tris- $\mathrm{HCl}$ buffer. (b) A plot of the absorbance ratio between 645 and $500 \mathrm{~nm}$ over different dilution factors $\left(\mathrm{C}_{0} / \mathrm{C}\right)$. 


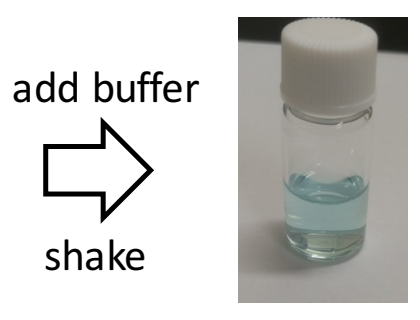

Size: $94.8 \pm 2.8 \mathrm{~nm}$

PDI : $0.23 \pm 0.005$

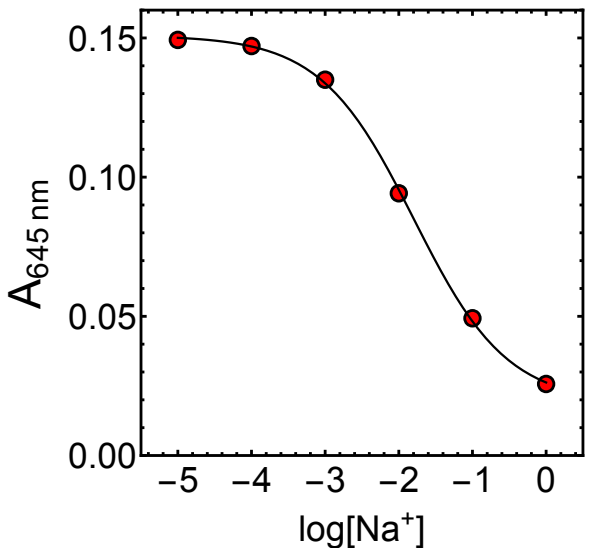

Figure S9. Resuspension of the dried PS-PEO $\mathrm{Na}^{+}$nanosensors by adding buffer solution and shaking the mixture with hand. The right part shows the response of the nanosensors to various $\mathrm{Na}^{+}$concentrations in absorbance mode.
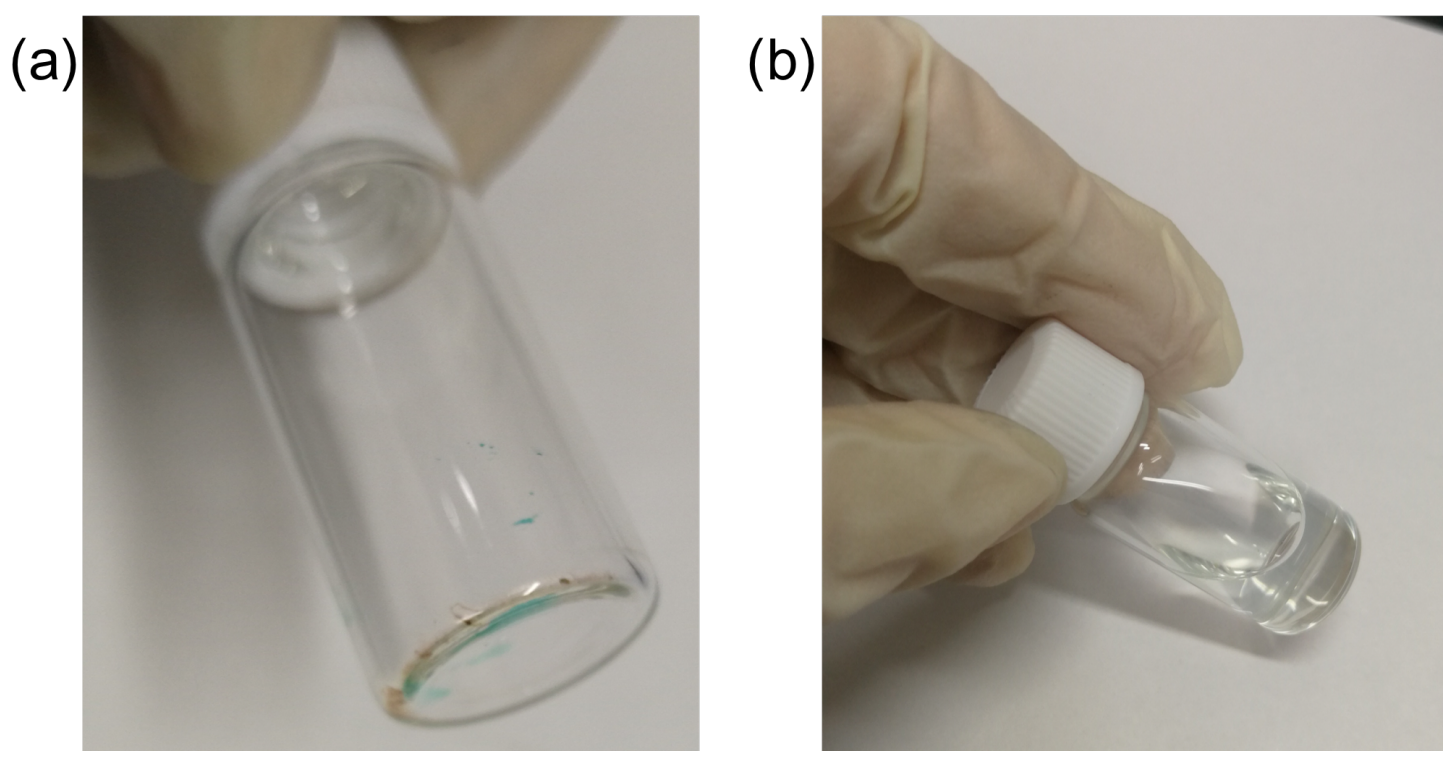

Figure S10. (a) Picture of the nanosensors containing Pluronic F-127 and DOS after drying with compressed air. The nanosensors contained the same amount of sensing components compared with the PS-PEO nanosensors in Figure S9. (b) Resuspension of the nanosensors containing Pluronic F127 and DOS by adding deionized water to the vial in (a) and shaking with hand. 
The ion-carrier stability constants in the PS-PEO nanodots were determined according to previously described methods (Anal. Chem. 2015, 87, 11587-11591). $\mathrm{Na}^{+}$response and $\mathrm{K}^{+}$responses were recorded in UV-vis absorption mode for two types of nanodots, one containing ionophore and the other not. Chromoinophore III was replaced by chromoionophore II, a less basic indicator, so that the response without ionophores could be seen.
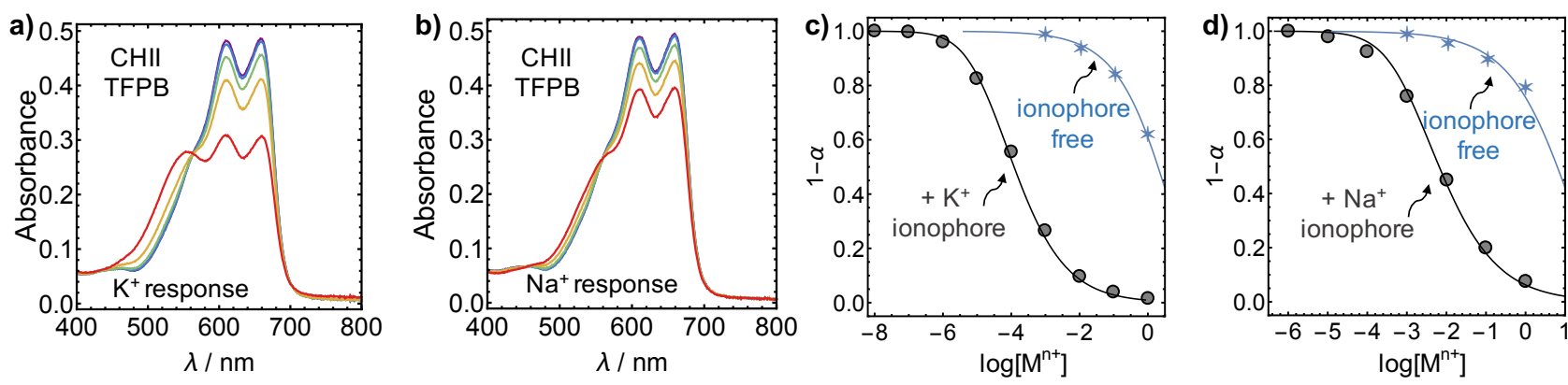

Figure S11. (a) UV-vis spectra of the PS-PEO nanodots doped with chromoionophore II (CHII), TFPB in pH 7.4 Tris- $\mathrm{HCl}$ solutions containing various concentrations of $\mathrm{K}^{+}$(from $1 \mathrm{mM}$ to $1 \mathrm{M}$ ). (b) UV-vis spectra of the PS-PEO nanodots doped with chromoionophore II (CHII), TFPB in $\mathrm{pH} 7.4$ Tris-HCl solutions containing various concentrations of $\mathrm{Na}^{+}$(from $1 \mathrm{mM}$ to $1 \mathrm{M}$ ). (c) Overlay of the $\mathrm{K}^{+}$response curves for the PS-PEO nanodtos with and without the $\mathrm{K}^{+}$ionophore. (d) Overlay of the $\mathrm{Na}^{+}$response curves for the PS-PEO nanodots with and without the $\mathrm{Na}^{+}$ ionophore. 
a)

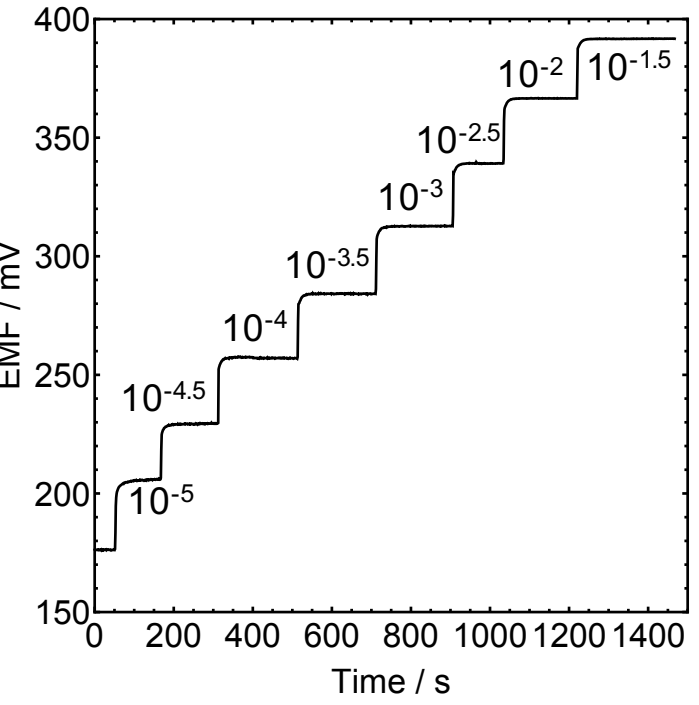

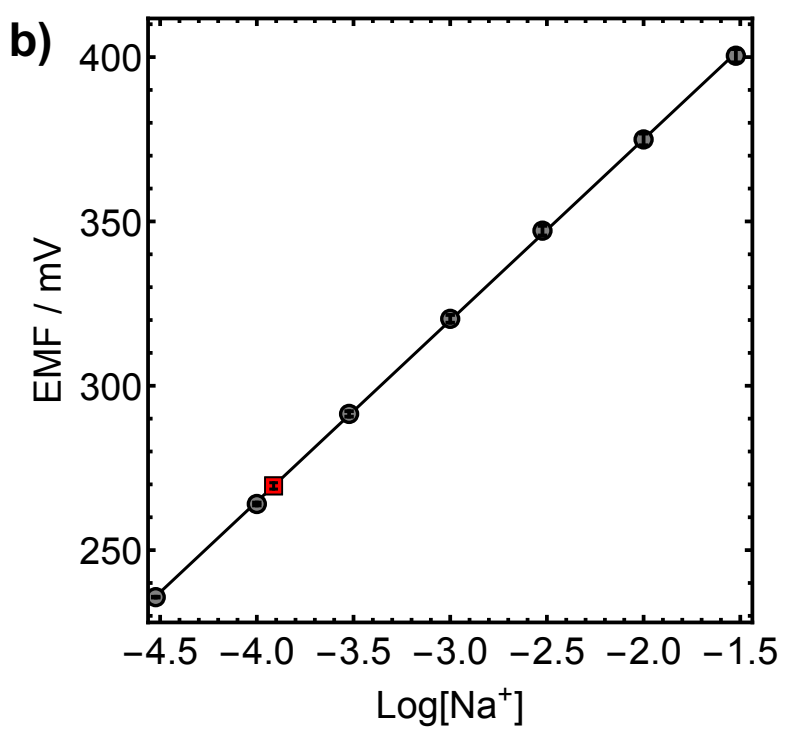
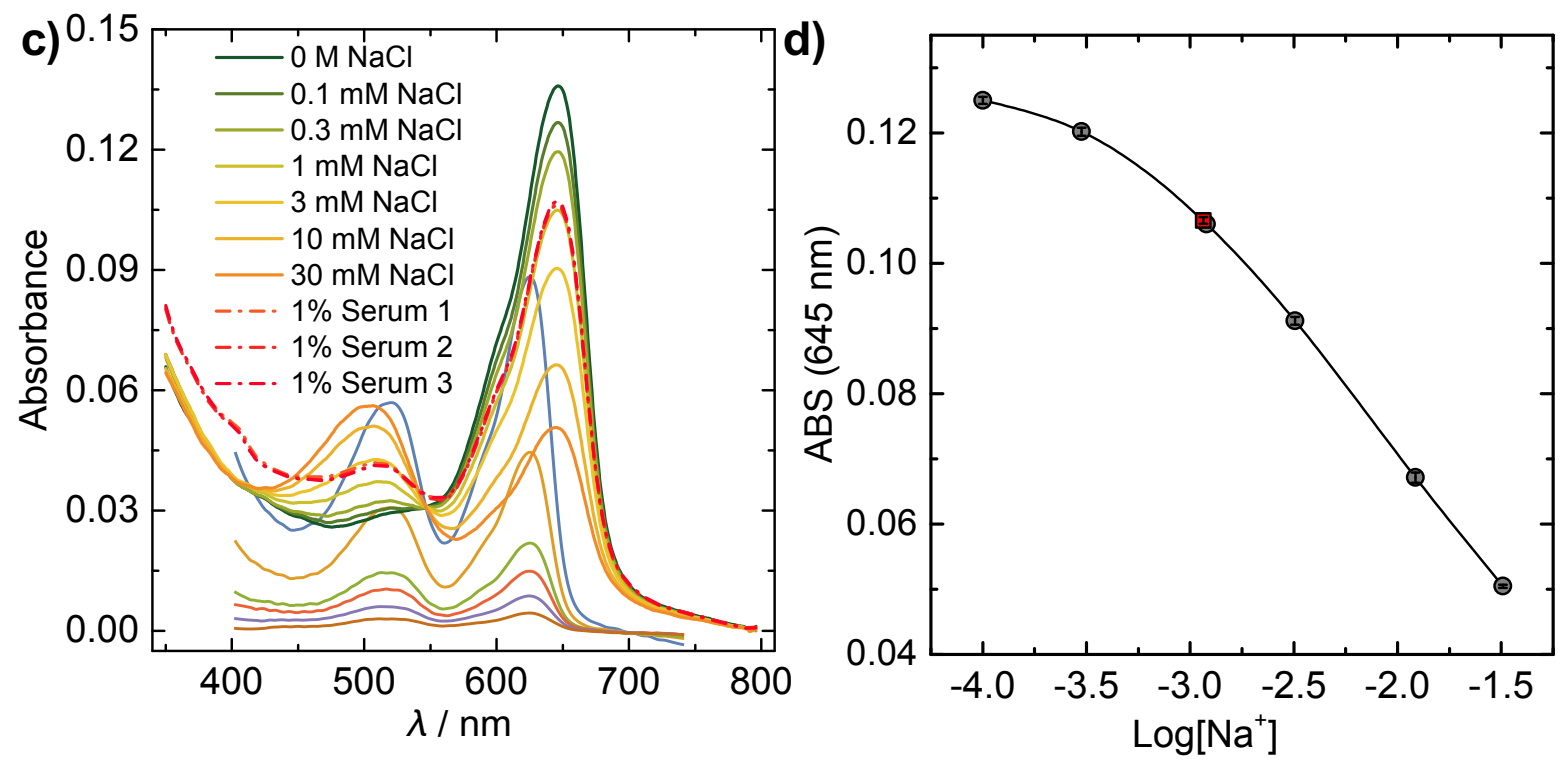

Figure S12. Determination of sodium ion concentrations in diluted blood serum with $\mathrm{Na}^{+}$-selective electrodes and the $\mathrm{Na}^{+}$nanosensors. (a): Potentiometric response of the $\mathrm{Na}^{+}$electrodes to increasing concentrations of $\mathrm{NaCl}$ as indicated. (b): Potentiometric calibration of the $\mathrm{Na}^{+}$electrodes. (c): Light absorption spectra of the $\mathrm{Na}^{+}$nanosensors in $\mathrm{pH}$ 7.4 Tris-HCl solutions containing a narrow concentration range of $\mathrm{Na}^{+}$ions and blood serum. (d): Calibration curve of the $\mathrm{Na}^{+}$-selective nanosensors. Red squares indicate the signals from the serum samples. Error bars represent standard deviations from three parallel measurements. 

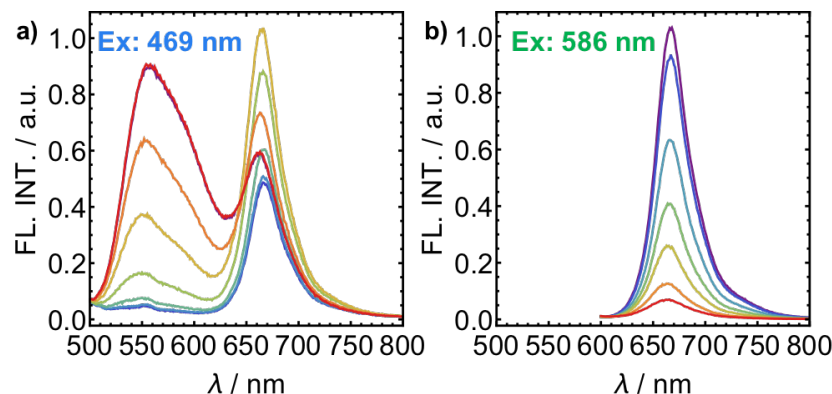

Figure S13. Response of the $\mathrm{K}^{+}$-selecitve nanodots in fluorescence mode with excitation at $469 \mathrm{~nm}$ (a) and $586 \mathrm{~nm}$ (b) in $\mathrm{pH} 7.4$ Tris- $\mathrm{HCl}$ buffer solutions.
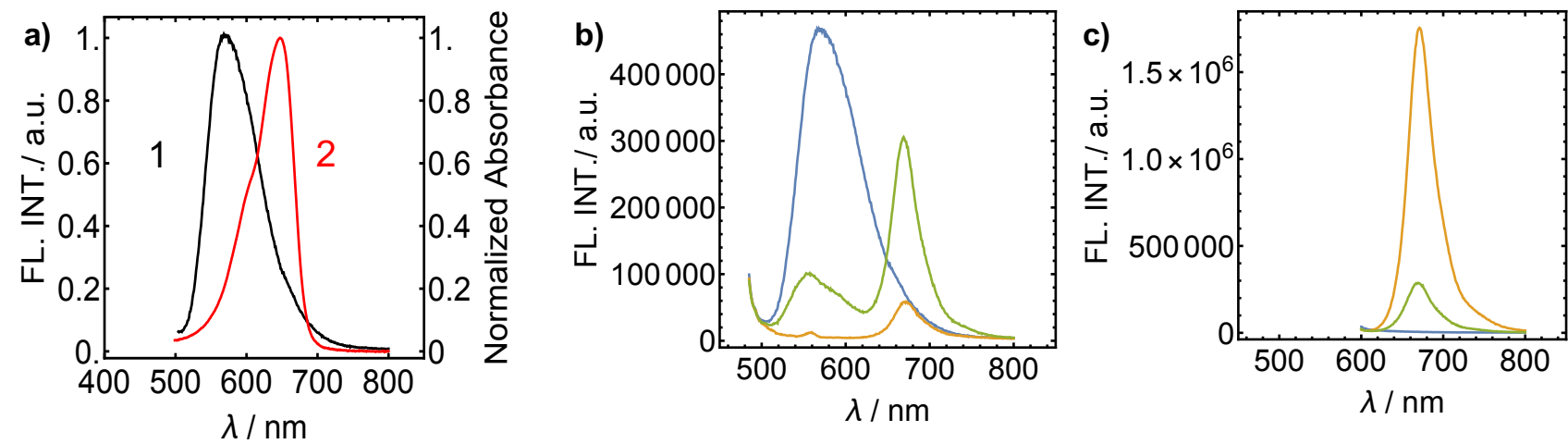

Figure S14. (a) Normalized fluorescence emission of the nanodots containing fully deprotonated chromoionophore III (in $1 \mathrm{mM} \mathrm{NaOH}$ ) and the normalized absorbance of the nanodots containing fully protonated chromoionophore III (in $1 \mathrm{mM} \mathrm{HCl}$ ). (b) Fluorescence emission spectra of the nanodots upon excitation at $469 \mathrm{~nm}$. The $\mathrm{pH}$ of the nanodots were adjusted to obtain different degree of protonation. Orange trace: fully protonated; blue trace: fully deprotonated; green trace: partially protonated. (c) Fluorescence emission spectra of the nanodots upon excitation at $586 \mathrm{~nm}$. The $\mathrm{pH}$ of the nanodots were adjusted to obtain different degree of protonation. Orange trace: fully protonated; blue trace: fully deprotonated; green trace: partially protonated. 

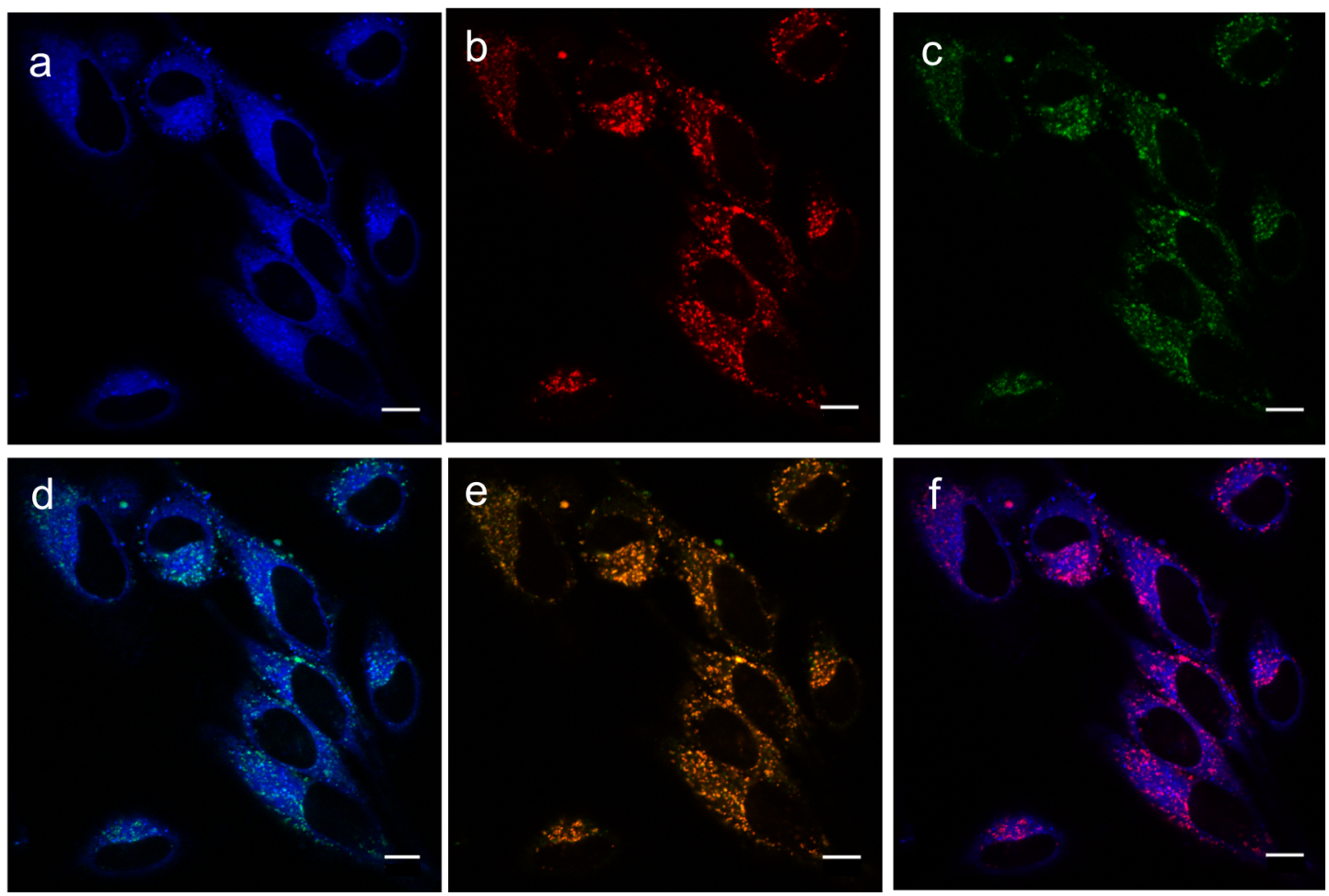

Figure S15. Confocal LSFM images of HeLa cells incubated with ER-Tacker Blue-White DPX (blue channel, a), the PS-PEO nanodots (red emission shown in b and greed channel shown in c), and the overlay of blue+green (d), green+red (e), blue+red (f). Scale bar: $10 \mu \mathrm{m}$. 

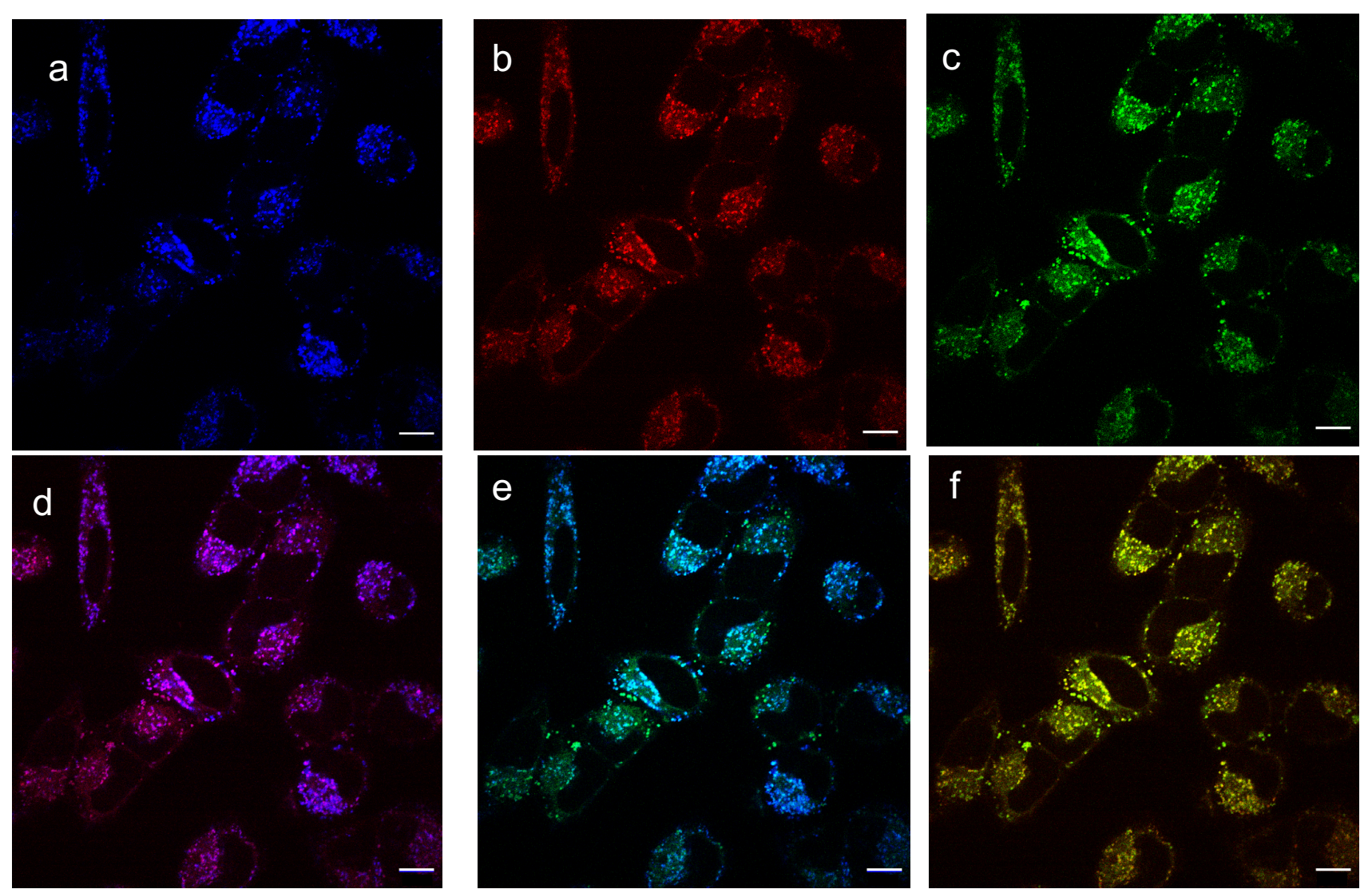

Figure S16. Confocal LSFM images of HeLa cells incubated with LysoTracker Blue DND-22 (blue channel, a), the PS-PEO nanodots mixed with $0.6 \mathrm{mg} / \mathrm{L} \mathrm{CPP} \mathrm{(red} \mathrm{emission} \mathrm{shown} \mathrm{in} \mathrm{b}$ and greed channel shown in c), and the overlay of blue+red (d), blue+green (e), red+green (f). Scale bar: $10 \mu \mathrm{m}$.

Table S1. Selectivity coefficients of the $\mathrm{Na}^{+}$and $\mathrm{K}^{+}$nanosensors

\begin{tabular}{|c|c|c|c|}
\hline \multicolumn{2}{|c|}{$\mathrm{Na}^{+}$-selective nanosensors } & \multicolumn{2}{c|}{$\mathrm{K}^{+}$-selective nanosensors } \\
\hline $\log K_{N a, K}^{O p t}$ & $-2.3 \pm 0.1$ & $\log K_{K, N a}^{O p t}$ & $-4.4 \pm 0.1$ \\
\hline $\log K_{N a, C a}^{O p t}$ & $-1.0 \pm 0.1)$ & $\log K_{K, C a}^{O p t}$ & $-4.8 \pm 0.1$ \\
\hline $\log K_{N a, L i}^{O p t}$ & $-2.8 \pm 0.1$ & & $-4.9 \pm 0.1$ \\
\hline $\log K_{N a, M g}^{O p t}$ & $-3.1 \pm 0.1)$ & $\log K_{K, L i}^{O p t}$ & $-5.4 \pm 0.1$ \\
\hline
\end{tabular}

The selectivity coefficients $\log \mathrm{K}_{\mathrm{ij}}^{\mathrm{Opt}}$, with $\mathrm{i}$ being the primary ion and $\mathrm{j}$ the interfering ion, was determined according to previous description (Anal. Chem. 1992, 64, 1805-1812) with $\alpha$ equal to 0.5 and pH 7.4. The coefficients in the parenthesis was estimated for the $\mathrm{Na}^{+}$nanosensors based on Pluronic F-127 and DOS in previous report (Anal. Chem. 2013, 85, 9932-9938). 